Article

\title{
Be Careful How You Do It: The Distinct Effects of Observational Monitoring and Interactional Monitoring on Employee Trust
}

\author{
Di Wu * and Zhongming Wang \\ School of Management, Zhejiang University, Hangzhou 310058, China; wangzm_zju@hotmail.com \\ * Correspondence: wudihw@163.com
}

Received: 10 July 2020; Accepted: 28 July 2020; Published: 29 July 2020

\begin{abstract}
Research shows that employee trust could be impacted by monitoring measures. We contend that these impacts could be contingent on how monitoring is exercised. Specifically, while the controlling elements in monitoring signal suspicion and undermine employee trust, the interactive elements facilitate the organization-employee reciprocation and strengthen employee trust. We drew evidence from 354 Chinese employees. The results showed that observational monitoring/interactional monitoring was negatively/positively related to employee trust and that employee psychological safety fully mediated these effects. The theoretical and practical implications of these findings are discussed.
\end{abstract}

Keywords: observational monitoring; interactional monitoring; trust; psychological safety

\section{Introduction}

Trust is key to sustainable organizational development. Over decades, a considerable amount of research has confirmed how a trustful workforce could benefit the organization in numerous ways. Meanwhile, a number of factors have been identified to have their respective influences on trust. The current study focuses on the impacts on employee trust from two types of monitoring, which also represent two types of leadership styles.

For leaders, monitoring is particularly important because it provides the information needed for critical decisions. There are a variety of ways to monitor, from CCTV cameras and wearable devices with GPS tracking systems, which are totally non-interactive, to interactive ways, such as subordinate reports on regular meetings and informal communication on social media platforms. According to Liao and Chun, these different approaches to monitoring can be categorized as observational monitoring $(\mathrm{OM})$ and interactional monitoring (IM) [1]. Underlying this typology, the classic transactional versus transformational leadership debate could find its place, as transactional leaders care more about what the subordinates have done, while, on top of that, transformational leaders are also concerned about what the subordinates have to say. Therefore, whereas transactional leaders use OM to assess and reward the contributions subordinates have made, transformational leaders rely on IM to extract valuable ideas and opinions from their followers. Because of the discrepancy in the way of information gathering, OM and IM would also affect employee trust differently because trust is highly fragile [2] and sensitive to how the trustors are treated.

We took the social exchange theory as the main perspective in the study. In the light of the social exchange theory, the relationships between people evolve as one party repays the good deeds of another party through a process of reciprocity [3]. It has been acknowledged that the quality of social exchange is often influenced by the quality of the relationship [4]. In this study, we contend that OM will negatively affect the relationship quality between the management and the employees, while IM will positively affect it. Using the data from a survey of 354 Chinese employees, we find that OM 
and IM do have distinct effects on employee trust, and that psychological safety has a mediating role to play in the process.

\section{Literature Review}

\subsection{The Typology of Monitoring}

For decades, organizational researchers and practitioners have been devoting efforts to finding better ways to monitor. In its essence, monitoring is about work information collection [5]. In early monitoring studies, scholars came to rather contradictory conclusions, with some findings indicating that monitoring negatively affects employee attitudes and performance [6], while other research showed that monitoring actually improves employee behaviors [7]. Given the great variety of means that the management can adopt to execute monitoring, this inconsistency in how monitoring may impact employee feelings and reactions becomes comprehensible, as different types of monitoring measures are likely to give rise to distinct outcomes. In this regard, Liao and Chun proposed their dichotomy of monitoring, which included virtually all monitoring measures and explained why they worked out differently [1]. They classified monitoring as either observational or interactional by defining observational monitoring $(\mathrm{OM})$ as gathering of work information without the direct input from subordinates and interactional monitoring (IM) as gathering with direct subordinate input. The current study adopted this typology in our investigation of how monitoring impacts employee trust in the management.

\subsection{Trust}

A vast number of studies have confirmed the benefits of trust for sustainable organizational development $[8,9]$. In terms of talent retention, employee trust has been identified as a positive factor for high organizational commitment $[10,11]$, which predicts a sustainable workforce. In innovation terms, trusting employees are contended to produce better innovation performance [1,12], which builds a sustainable competitive advantage for the organization in the long run.

By the classic definition, trust represents the willingness of one person to be vulnerable to the actions of another party [13]. From a social exchange perspective, trust signals the relationship quality between the two parties [4]. As they both fulfill their mutual obligations in their interactions, the relationship between the two parties is strengthened and their trust in each other deepened [14]. When viewed as a psychological state, trust has been considered to include a cognitive component and an affective component $[15,16]$. In the case of monitoring, we argue that both components of trust will be impacted by the way monitoring is implemented.

\subsection{Observational Monitoring and Trust in Management}

While most early monitoring research did not make the distinction between OM and IM, some works were clearly focusing on the observational type, especially when their research topics involved employee privacy or data surveillance. As a matter of fact, advancement in modern information technology has largely enabled the management to obtain work information without active participation of employees, making OM much easier. Although sometimes perceived as invasive, these OM practices like electronic monitoring have been considered conducive to encouraging employee compliance and preventing counterproductive work behaviors [17]. However, as emerging technologies create novel OM measures and empower existing ones, researchers have started to unfold the undesired side of $\mathrm{OM}$, which is claimed to be responsible for a series of negative outcomes, especially in psychological terms, e.g., higher stress [18], anxiety [19], lower felt trust [20], and reduced satisfaction, intrinsic work motivation, and affective organizational commitment [21]. In the light of these findings, the current study contends that OM will undermine employee trust because it will hurt both their cognitive trust as well as affective trust in their management. For one thing, OM breaches the psychological contract on which cognitive trust is built [22]. For the other, the sense of hierarchy reinforced 
by $\mathrm{OM}$ measures psychologically estranges employees from the management, which obstructs the establishment and development of their affective trust in their management [23]. Hence, we propose the following hypothesis.

Hypothesis 1. OM is negatively associated with employees' trust in their management.

\subsection{Interactional Monitoring and Trust in Management}

Interactional monitoring involves direct solicitation of work information from the subordinates [1] and is just as common as OM in any workplace. However, for this type of monitoring, we argue that IM activities will improve employees' cognitive and affective trust in their management. Firstly, the enhanced perception of fairness brought about by IM encourages employees to approve of such policies of their management and cognitively affirm their trustworthiness [24]. As the management needs the work information to form the impression of a particular employee, an opportunity for the latter to participate in the process is often regarded as both significant and necessary, especially when s/he is an out-group member from the perspective of the Leader-Member Exchange theory [25]. When the employees know that the management is trusting them to be part of the process, they will likely appreciate the fairness and thus be more trustful. Secondly, the feeling of being respected by the management in IM processes is conducive to the cultivation of employee affective trust. Research shows that emotional connections and trust are better built when subordinates perceive that their concerns and well-being are fully considered by their leaders when decisions are being made [15]. Using data from a three-wave survey, Łopaciuk-Gonczaryk also confirmed that interacting with people is conducive to the development of trust [26]. In this vein, as employees are granted the chance to articulate their own concerns and viewpoints, they are more likely to feel that they are treated as equals. Such feelings strengthen the relationship between the two parties, and the affective trust should thus be elevated. Hence, we propose the following hypothesis.

Hypothesis 2. IM is positively associated with employees' trust in their management.

\subsection{The Mediating Role of Psychological Safety}

Psychological safety describes the perception of consequences of engaging in interpersonal risk-taking activities, particularly in the workplace [27]. It is contended that high psychological safety will lead to multiple positive employee outcomes, e.g., emotion stability, leader relations, work engagement, etc. [28]. In the case of monitoring, this study contends that psychological safety perceived by employees mediates the distinct effects that the two types of monitoring have on employee trust.

Research has shown that leadership styles and behaviors exert a significant influence on the level of employee psychological safety [27]. Therefore, it is likely that OM and IM, which reflect different leadership styles, will impact employee psychological safety differently. Specifically, the findings of a study conducted in Hong Kong and US financial companies indicate that servant leadership, which emphasizes the leader's role of listening and sympathizing, is positively associated with the subordinates' psychological safety level [29]. In addition, other studies also show that leader-member interactions are beneficial to the improvement of member psychological safety [30,31]. Drawing from these conclusions, we argue that employees who experience higher IM are likely to feel higher levels of psychological safety because, during the interactions with their supervisors, they have a much better chance to have their voice heard and concerns heeded. Conversely, as OM deprives the employees of their opportunity to speak for themselves, the experience of exclusion may lead to concerns of one-sided observations and biased conclusions, resulting in low psychological safety among the employees.

Psychological safety and trust are a pair of similar concepts, but with different focuses. In multiple studies, researchers have used the terms "social climate of trust" [32] or "trusting relationships" [33] 
to describe or relate to psychological safety. With regard to their causal relationship, although psychological safety has usually been deemed as an outcome of trust $[29,34]$, we argue that the reversed causal relationship could also be true. When employees perceive a high level of psychological safety, they are not afraid of taking interpersonal risks, believing that others, including the management, will not take advantage of them. As such an experience of psychological safety greatly resembles the feelings of being trusted, from the perspective of social exchange theory, the employees will reciprocate by trusting those around them, including the management. Hence, we have the following hypothesis and propose the mediation model in Figure 1.

Hypothesis 3. Employees' psychological safety mediates the relationship between OM/IM and their trust in management.

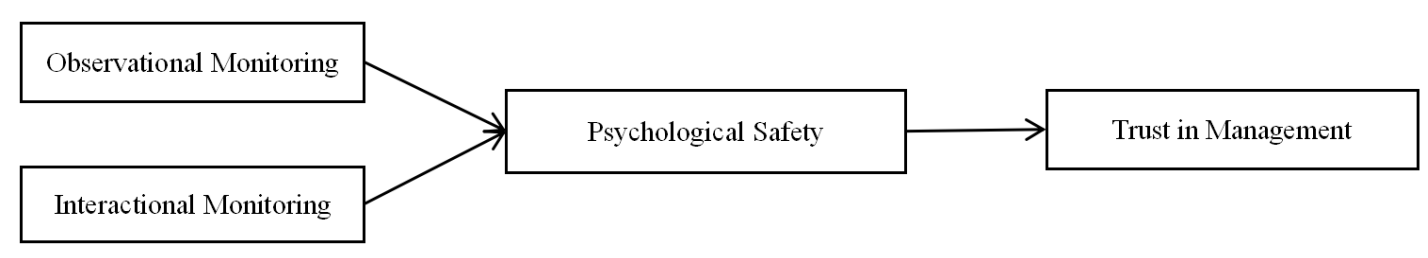

Figure 1. The mediation model.

\section{Method}

\subsection{Sampling and Data Collection}

We used questionnaires to collect data for this study. Adopting the convenience sampling approach, we sampled from employees working in or near six different office buildings in Wenzhou, a city in China, in August 2019. At each office building, we visited cafes, convenience stores, bus stations, and shared bike parking spots nearby to find random passers-by to fill out the electronic version of our survey using the tablet computer we provided. To each potential sample, we quickly introduced ourselves and described the general purpose of this research. Before they started to answer the questionnaire, we made sure that they were currently working in a company which they did not own. Upon finishing the survey, financial rewards were provided. Data were directly recorded in our tablet computer with a total of 376 submissions. Then, we followed the data verification procedures by identifying invalid questionnaires with the following problems: (1) Incomplete submissions with unanswered questions; (2) extreme submissions with all items rated at a same level (e.g., 5 on all items); (3) reckless submissions with contradictory ratings (e.g., 1 and 5) on items that measure the same construct. After removing the surveys with the above issues, 354 valid samples were retained for further analysis.

The total 354 respondents included 192 males ( $54 \%$ of the total sample) and 162 females (46\%). The average age for the respondents was 32.39 ( $\mathrm{SD}=9.84)$. The average organizational tenure for them was 6.99 years $(\mathrm{SD}=5.62)$. By comparing with the same types of data (employee gender, age, and organizational tenure) used in other published studies conducted in China [35-37], we confirmed the sample representativeness of our data.

\subsection{Measures}

We adopted validated scales from previous studies to measure the four focal variables in our survey. Because the survey was conducted in China, we followed a systematic translation and back-translation procedure [38] to translate all scales into Chinese.

We measured OM and IM using Liao and Chun's ten-item monitoring scale with five items measuring each dimension [1]. Sample items are "My supervisor keeps pretty close tabs on me" and "My supervisor often meets me to discuss work progress". The Cronbach's $\alpha$ of the OM scale was 0.84 and 0.74 for the IM scale. 
Respondents rated their trust in management on the scale developed by [39]. This scale consists of ten items, with three of them being reverse-scored. A sample item on the trust scale is "I would tell the management about mistakes I've made on the job, even if they could damage my reputation". The Cronbach's $\alpha$ of the scale was 0.90 .

We adapted Edmondson's seven-item scale to measure respondents' level of psychological safety [40]. Among the seven items, three are reverse-scored. A sample item is "It is difficult for me to ask others for help". The Cronbach's $\alpha$ of the scale was 0.80 . All constructs were measured on a five-point scale, with 1 meaning "strongly disagree" to 5 meaning "strongly agree".

Following previous studies that also treated trust in management as a dependent variable [41-43], we controlled gender, age, and organizational tenure, which may be correlated with employee trust in management.

\section{Results}

\subsection{Descriptive Statistics and Correlations}

Descriptive statistics (means and standard deviations) and correlations of all variables are displayed in Table 1. The results show that gender, age, and tenure are not significantly correlated with the outcome variable, i.e., trust in management. Therefore, we decided to exclude them in the following analysis.

Table 1. Descriptive statistics and correlations.

\begin{tabular}{|c|c|c|c|c|c|c|c|c|}
\hline & Mean & S.D. & 1 & 2 & 3 & 4 & 5 & 6 \\
\hline 1. Gender & 0.54 & 0.50 & & & & & & \\
\hline 2. Age & 32.39 & 9.84 & 0.01 & & & & & \\
\hline 3. Organizational tenure & 6.99 & 5.62 & 0.03 & $0.75 * *$ & & & & \\
\hline 4. Observational monitoring & 2.70 & 0.83 & 0.02 & -0.01 & -0.01 & & & \\
\hline 5. Interactional monitoring & 3.91 & 0.60 & 0.05 & -0.08 & $-0.11 *$ & $-0.30^{* *}$ & & \\
\hline 6. Trust in management & 3.49 & 0.71 & -0.08 & 0.01 & -0.01 & $-0.17^{* *}$ & $0.25^{* *}$ & \\
\hline 7. Psychological safety & 3.79 & 0.59 & 0.03 & -0.07 & -0.04 & $-0.43^{* *}$ & $0.54^{* *}$ & $0.41^{* *}$ \\
\hline
\end{tabular}

We examined the discriminant and convergent validity of the variables in this study via a confirmatory factor analysis (CFA). As displayed in Table 2, the four-factor model provided the best fit to the data. All factor loadings with bootstrapping were above 0.50 and statistically significant $(p<0.001)$. Thus, sufficient justification for further data analysis is provided by the CFA results.

Table 2. The goodness fit index of measurement models.

\begin{tabular}{ccccccccc}
\hline Measurement Model & $\boldsymbol{\chi} \mathbf{2}$ & $\boldsymbol{d f}$ & $\boldsymbol{\Delta} \boldsymbol{\chi} \mathbf{2}$ & $\boldsymbol{\Delta} \boldsymbol{d f}$ & $\mathbf{C F I}$ & IFI & TLI & RMSEA \\
\hline Four-factor & 350.88 & 318 & $/$ & $/$ & 0.99 & 0.99 & 0.99 & 0.02 \\
Three-factor & 825.71 & 321 & $474.83^{* * *}$ & 3 & 0.84 & 0.85 & 0.83 & 0.07 \\
Two-factor & 1093.24 & 323 & $742.36^{* * *}$ & 5 & 0.76 & 0.76 & 0.74 & 0.08 \\
One-factor & 1657.87 & 324 & $1306.99^{* * *}$ & 6 & 0.59 & 0.59 & 0.55 & 0.11 \\
\hline \multicolumn{8}{c}{ Note. ${ }^{* * *} p<0.001}$.
\end{tabular}

\subsection{Examining the Main Effects}

Table 3 shows the regression results of the main effects, i.e., the effects of OM and IM on trust in management. Specifically, the effect of $\mathrm{OM}$ on trust in management was significantly negative, and the effect of IM on trust in management was significantly positive. Therefore, Hypothesis 1 and Hypothesis 2 were supported. 
Table 3. Regression results.

\begin{tabular}{cccc}
\hline DV & Trust in Management & Psychological Safety & Trust in Management \\
\hline Main effect & & & \\
Observational & $-0.09^{*}$ & $-0.21^{* * *}$ & 0.00 \\
monitoring & $0.25^{* * *}$ & $0.45^{* * *}$ & 0.04 \\
Interactional monitoring & & $0.48^{* * *}$ \\
Mediating effect & $0.07^{* * *}$ & 0.37 & 0.17 \\
Psychological safety & $13.52^{* * *}$ \\
R2 & $103.58^{* * *}$ & $40.92^{* * *}$ \\
F & Not &
\end{tabular}

Note: $\mathrm{N}=354 .{ }^{*} p<0.05,{ }^{* * *} p<0.001$.

\subsection{Examining the Mediation Model}

We tested the mediation model following the procedures proposed by Preacher and Hayes [44]. First, we examined the relationship between the independent variables (OM and IM) and the mediator variable (psychological safety). As shown in Table 3, OM was negatively related to psychological safety, and IM was positively related to it. Second, we examined the relationship between the mediator variable (psychological safety) and dependent variable (trust in management) after controlling the effect of the two independent variables (OM and IM) toward the dependent variable. The results showed that psychological safety was positively associated with trust in management. Thus, the mediation model in Hypothesis 3 was supported. Moreover, as the mediator entered the model, OM and IM were no longer significantly related to employee trust in management. Therefore, psychological safety fully mediated the effect of OM and IM on employee trust in management.

\section{Discussion}

In the current study, we empirically investigated the impacts of OM and IM on employee trust in management and further probed into the underlying mechanism, with psychological safety being a mediator. Our data showed that employee trust in management was negatively associated with OM and positively with IM. The results also supported our hypothesis that psychological safety plays a mediating role in the relationship between the two monitoring types and trust. As the relationships between trust and the two monitoring variables become statistically insignificant when psychological safety enters the regression model, the model is considered to be a full mediation.

\section{Theoretical Contributions}

The current study has three theoretical contributions. Firstly, it clarifies the inconsistent effects of monitoring on trust in existing literature by separating the effects from two distinct types of monitoring. Over decades, scholars have been discussing about the relationship between monitoring and trust. Research shows that companies that keep better track of the process yield higher employee trust than those that merely focus on results [45]. In comparison, other scholars argue that monitoring either becomes redundant in the case of high trust, or impairs trust as it implies suspicion [46]. While both complementary and supplementary views are based on solid theoretical grounds, the current study follows the monitoring typology proposed by Liao and Chun [1] and contributes to the monitoring-trust literature by distinguishing the distinct impacts of OM and IM, and thus helps to clarify the inconsistency in the findings regarding this topic.

Secondly, it deepens our understanding of the relationship between psychological safety and trust. Edmondson compared these two concepts and stated that they "have much in common" [34], as they are both psychological states that concern risk and vulnerability, and are both positively associated with performance at various levels. In past studies, most scholars tend to consider psychological safety as an outcome of trust $[29,47]$. While the idea of trust enhancing psychological safety has been widely acknowledged, the current study brings new insights by revealing that the reversed causality 
could also be possible. That is, when employees perceive a high level of psychological safety, they are more inclined to trust their management because, after all, trusting others is in its very nature a risk-taking behavior.

Thirdly, it provides new empirical evidence for the classic transactional versus transformational leadership discussion. Since their introduction by Burns [48], transactional leadership and transformational leadership have been the most widely studied concepts in this field. While many scholars have endeavored to determine which type is more effective under what particular circumstances [49,50], others hold that the best leader should be ambidextrous with both [51]. The current study enters this discussion by narrowing down leadership behaviors to the specific activity of work information gathering, namely monitoring. Whereas $\mathrm{OM}$ is often exercised by transactional leaders who constantly watch over their followers and correct the mistakes that they observe, IM is more of a transformational leadership behavior, which involves leaders soliciting opinions and concerns from their followers. By presenting our findings of the distinct consequences of two monitoring types, this study helps us better understand transactional and transformational leadership in the context of monitoring.

\section{Managerial Implications}

While new information technologies are making monitoring tools increasingly accessible and affordable, the management in organizations should be careful about how they make use of these tools. Particularly, if the management expects to maintain a sustainable workforce, the trust from the monitored side is a critical factor, which could be severely affected by how the monitoring measures are put in place. As the findings of this study suggest, if the management monitors the employees through one-sided observation, it may end up with a less trusting workforce. On the contrary, if the management could support and include the contributions from the employees in the collection of work information, the employees may fear less and trust more.

Whereas more supervisor-subordinate interaction is encouraged to ensure higher trust, the findings of this study also confirm the positive effect of psychological safety on trust. In this regard, as multiple antecedents of psychological safety have been identified over years of academic endeavors, the management can seek insights from the previous research findings to learn what they can do, in addition to more IM, to hoist the level of psychological safety for their employees and increase their trust.

\section{Limitations and Future Directions}

The findings of the current study should be considered with the following limitations.

First, due to the cross-sectional nature of the study, causal conclusions cannot be drawn from the analysis that we have conducted. Therefore, we suggest that future research adopts a longitudinal or experimental design to empirically study this topic. Second, common method bias might be an issue that undermines the validity of this study because all survey questions were answered by the same person through a self-report manner. In efforts to tackle this issue, we followed procedural remedies during the study [52], e.g., stressing that the data will be used only for research purposes, and that there are no right or wrong answers to our questions. We also ran a one-factor model using all our data and its poor fit (see Table 2) rejected that any single factor could explain a majority of the variance [53]. Hence, we believe that common method bias should not be a problem that negates our findings.

Author Contributions: D.W., as the first author, proposed the idea and basic model for this research, collected and analyzed the data, drafted the work and revised it. Z.W. contributed in the theory part, supervised this research and helped revise it. Both authors have read and agreed to the published version of the manuscript.

Funding: This research received no external funding.

Conflicts of Interest: The authors declare no conflict of interest. 


\section{References}

1. Liao, E.Y.; Chun, H. Supervisor monitoring and subordinate innovation. J. Organ. Behav. 2016, 37, $168-192$. [CrossRef]

2. Haselhuhn, M.P.; Schweitzer, M.E.; Kray, L.J.; Kennedy, J.A. Perceptions of high integrity can persist after deception: How implicit beliefs moderate trust erosion. J. Bus. Ethics 2017, 145, 215-225. [CrossRef]

3. Cropanzano, R.; Anthony, E.L.; Daniels, S.R.; Hall, A.V. Social exchange theory: A critical review with theoretical remedies. Acad. Manag. Ann. 2017, 11, 479-516. [CrossRef]

4. Chernyak-Hai, L.; Rabenu, E. The new era workplace relationships: Is social exchange theory still relevant? Ind. Organ. Psychol. 2018, 11, 456-481. [CrossRef]

5. Holt, M.; Lang, B.; Sutton, S.G. Potential employees' ethical perceptions of active monitoring: The dark side of data analytics. J. Inf. Syst. 2017, 31, 107-124. [CrossRef]

6. McParland, C.; Connolly, R. Dataveillance in the workplace: Managing the impact of innovation. Bus. Syst. Res. J. 2020, 11, 106-124. [CrossRef]

7. Bhave, D.P. The invisible eye? Electronic performance monitoring and employee job performance. Pers. Psychol. 2013, 67, 605-635. [CrossRef]

8. Radomska, J.; Wołczek, P.; Sołoducho-Pelc, L.; Silva, S. The impact of trust on the approach to management-A case study of creative industries. Sustainability 2019, 11, 816. [CrossRef]

9. Bulińska-Stangrecka, H.; Bagieńska, A. HR practices for supporting interpersonal trust and its consequences for team collaboration and innovation. Sustainability 2019, 11, 4423. [CrossRef]

10. Jiang, Z.; Gollan, P.J.; Brooks, G. Relationships between organizational justice, organizational trust and organizational commitment: A cross-cultural study of China, South Korea and Australia. Int. J. Hum. Resour. Manag. 2017, 28, 973-1004. [CrossRef]

11. Tekingündüz, S.; Top, M.; Tengilimoğlu, D.; Karabulut, E. Effect of organisational trust, job satisfaction, individual variables on the organisational commitment in healthcare services. Total Qual. Manag. Bus. Excell. 2017, 28, 522-541. [CrossRef]

12. Yu, M.; Mai, Q.; Tsai, S.; Dai, Y. An empirical study on the organizational trust, employee-organization relationship and innovative behavior from the integrated perspective of social exchange and organizational sustainability. Sustainability 2018, 10, 864. [CrossRef]

13. Mayer, R.C.; Davis, J.H.; Schoorman, F.D. An integrative model of organizational trust. Acad. Manag. Rev. 1995, 20, 709-734. [CrossRef]

14. Cropanzano, R.; Mitchell, M.S. Social exchange theory: An interdisciplinary review. J. Manag. 2005, 5, 874-900. [CrossRef]

15. Lu, J.; Zhang, Z.; Jia, M. Does servant leadership affect employees' emotional labor? A social information-processing perspective. J. Bus. Ethics 2019, 159, 507-518. [CrossRef]

16. Ren, S.G.; Shu, R.; Bao, Y.C.; Chen, X.H. Linking network ties to entrepreneurial opportunity discovery and exploitation: The role of affective and cognitive trust. Int. Entrep. Manag. J. 2016, 12, 465-485. [CrossRef]

17. Tomczak, D.L.; Lanzo, L.A.; Aguinis, H. Evidence-based recommendations for employee performance monitoring. Bus. Horiz. 2018, 61, 251-259. [CrossRef]

18. Thiel, C.E.; MacDougall, A.E.; Bagdasarov, Z. Big (Benevolent) Brother: Overcoming the drawbacks of employee monitoring through ethical administration. Organ. Dyn. 2019, 48, 19-28. [CrossRef]

19. Becker, W.J.; Belkin, L.Y.; Conroy, S.A.; Tuskey, S. Killing me softly: Organizational e-mail monitoring expectations' impact on employee and significant other well-being. J. Manag. 2019. [CrossRef]

20. Bernstrøm, V.H.; Svare, H. Significance of monitoring and control for employees' felt trust, motivation, and mastery. Nord. J. Work. Life Stud. 2017, 7, 29-49. [CrossRef]

21. Jiang, H.; Tsohou, A.; Siponen, M.; Li, Y. Examining the side effects of organizational Internet monitoring on employees. Internet Res. 2020. ahead-of-print. [CrossRef]

22. Rani, H.; Arain, G.A.; Kumar, A.; Shaikh, I.R. Interplay between trust and distrust in the workplace: Examining the effect of psychological contract breach on organizational disidentification. J. Asia Bus. Stud. 2018, 12, 1-16. [CrossRef]

23. Webber, S.S. Development of cognitive and affective trust in teams: A longitudinal study. Small Group Res. 2008, 39, 746-769. [CrossRef] 
24. Lau, C.M.; Tan, S.L.C. The effects of procedural fairness and interpersonal trust on job tension in budgeting. Manag. Account. Res. 2006, 17, 171-186. [CrossRef]

25. Wayne, S.J.; Green, S.A. The effects of leader-member exchange on employee citizenship and impression management behavior. Hum. Relat. 1993, 46, 1431-1440. [CrossRef]

26. Łopaciuk-Gonczaryk, B. Does participation in social networks foster trust and respect for other people-evidence from poland. Sustainability 2019, 29, 1733. [CrossRef]

27. Edmondson, A.C.; Lei, Z. Psychological safety: The history, renaissance, and future of an interpersonal construct. Soc. Sci. Electron. Publ. 2014, 1, 23-43. [CrossRef]

28. Frazier, M.L.; Fainshmidt, S.; Klinger, R.L.; Pezeshkan, A.; Vracheva, V. Psychological safety: A meta-analytic review and extension. Pers. Psychol. 2017, 70, 113-165. [CrossRef]

29. Schaubroeck, J.; Lam, S.S.K.; Peng, A.C. Cognition-based and affect-based trust as mediators of leader behavior influences on team performance. J. Appl. Psychol. 2011, 96, 863-871. [CrossRef]

30. Roussin, C.J. Increasing trust, psychological safety, and team performance through dyadic leadership discovery. Small Group Res. 2008, 39, 224-248. [CrossRef]

31. Edmondson, A.C.; Mogelof, J.P. Explaining psychological safety in innovation teams. In Creativity and Innovation in Organizations; Thompson, L., Choi, H., Eds.; Erlbaum: Mahwah, NJ, USA, 2005; pp. 109-136.

32. Collins, C.J.; Smith, K.G. Knowledge exchange and combination: The role of human resource practices in the performance of high-technology firms. Acad. Manag. J. 2006, 49, 544-560. [CrossRef]

33. Gong, Y.; Cheung, S.; Wang, M.; Huang, J. Unfolding the proactive process for creativity: Integration of the employee proactivity, information exchange, and psychological safety perspectives. J. Manag. 2012, 38, 1611-1633. [CrossRef]

34. Edmondson, A.C. Psychological Safety, Trust and Learning: A Group-Level Lens, In Trust and Distrust in Organizations: Dilemmas and Approaches; Kramer, R., Cook, K., Eds.; Russell Sage Foundation: New York, NY, USA, 2004; pp. 239-272.

35. Shin, S.J.; Kim, T.Y.; Lee, J.Y.; Bian, L. Cognitive team diversity and individual team member creativity: A cross-level interaction. Acad. Manag. J. 2012, 55, 197-212. [CrossRef]

36. Chung, G.H.; Choi, J.N.; Du, J. Tired of innovations? Learned helplessness and fatigue in the context of continuous streams of innovation implementation. J. Organ. Behav. 2017, 38, 1130-1148. [CrossRef]

37. Jiang, Z.; Hu, X.; Wang, Z.; Jiang, X. Knowledge hiding as a barrier to thriving: The mediating role of psychological safety and moderating role of organizational cynicism. J. Organ. Behav. 2019, 40, 800-818. [CrossRef]

38. Brislin, R.W.; Lonner, W.; Thorndike, R. Cross-Cultural Methods; John Wiley and Sons: New York, NY, USA, 1973.

39. Mayer, R.C.; Gavin, M.B. Trust in management and performance: Who minds the shop while the employees watch the boss. Acad. Manag. J. 2005, 48, 874-888. [CrossRef]

40. Edmondson, A.C. Psychological safety and learning behavior in work teams. Adm. Sci. Q. 1999, 44, 350-383. [CrossRef]

41. Agrawal, R.K. Do ethical climates impact trust in management? A study in Indian context. Int. J. Organ. Anal. 2017, 25, 804-824. [CrossRef]

42. Hu, X.; Jiang, Z. Employee-oriented HRM and voice behavior: A moderated mediation model of moral identity and trust in management. Int. J. Hum. Resour. Manag. 2018, 29, 746-771. [CrossRef]

43. Zhang, Y.; Long, L.; Wu, T.; Huang, X. When is pay for performance related to employee creativity in the Chinese context? The role of guanxi HRM practice, trust in management, and intrinsic motivation. J. Organ. Behav. 2015, 36, 698-719. [CrossRef]

44. Preacher, K.J.; Hayes, A.F. Asymptotic and resampling strategies for assessing and comparing indirect effects in multiple mediator models. Behav. Res. Methods 2008, 40, 879-891. [CrossRef] [PubMed]

45. Gittell, J.H. Paradox of coordination and control. Calif. Manag. Rev. 2000, 42, 101-117. [CrossRef]

46. Weibel, A.; den Hartog, D.N.; Gillespie, N.; Searle, R.; Six, F.; Skinner, D. How do controls impact employee trust in the employer. Hum. Resour. Manag. 2016, 55, 437-462. [CrossRef]

47. Li, A.N.; Tan, H.H. What happens when you trust your supervisor? mediators of individual performance in trust relationships. J. Organ. Behav. 2013, 34, 407-425. [CrossRef]

48. Burns, J.M. Leadership; Harper \& Row: New York, NY, USA, 1978.

49. Prasad, B.; Junni, P. CEO transformational and transactional leadership and organizational innovation: The moderating role of environmental dynamism. Manag. Decis. 2016, 54, 1542-1568. [CrossRef] 
50. Lan, T.-S.; Chang, I.-H.; Ma, T.-C.; Zhang, L.-P.; Chuang, K.-C. Influences of transformational leadership, transactional leadership, and patriarchal leadership on job satisfaction of cram school faculty members. Sustainability 2019, 11, 3465. [CrossRef]

51. Luo, B.; Zheng, S.; Ji, H.; Liang, L. Ambidextrous leadership and TMT-member ambidextrous behavior: The role of TMT behavioral integration and TMT risk propensity. Int. J. Hum. Resour. Manag. 2018, 29, 338-359. [CrossRef]

52. Podsakoff, P.M.; MacKenzie, S.B.; Lee, J.; Podsakoff, N.P. Common method biases in behavioral research: A critical review of the literature and recommended remedies. J. Appl. Psychol. 2003, 88, 879-903. [CrossRef]

53. Harman, H.H. Modern Factor Analysis; University of Chicago Press: Chicago, CO, USA, 1976.

(C) 2020 by the authors. Licensee MDPI, Basel, Switzerland. This article is an open access article distributed under the terms and conditions of the Creative Commons Attribution (CC BY) license (http://creativecommons.org/licenses/by/4.0/). 